\title{
Erratum
}

\section{How to bring your kids up sadomasochist: Intimate-partner violence and the Twilight phenomenon}

\section{Frann Michel}

Psychoanalysis, Culture \& Society (2012) 17, 111. doi:10.1057/pcs.2011.19

Correction to: Psychoanalysis, Culture \& Society (2011) 16, 431.

doi: $10.1057 /$ pcs.2011.16

Please note that in the first paragraph of the above Field Note the American Psychiatric Association is referred to. The sentence concerned should have read as follows 'In her essay 'How to Bring Your Kids Up Gay: The War on Effeminate Boys,' Sedgwick notes that the removal of homosexuality from the Diagnostic and Statistical Manual (1980) (DSM-III) was accompanied by increasing concern about gender-variant children and the fear that such children would grow up to be queer. 